\title{
Formation of Chromate Conversion Coatings on Aluminum and Its Alloys
} An In Situ XANES Study

\author{
H. S. Isaacs, ${ }^{a, * *}$ K. Sasaki, ${ }^{\text {b,* }}$ C. S. Jeffcoate, ${ }^{\text {b, } *}$ V. Laget, ${ }^{b}$ and R. Buchheit ${ }^{\mathrm{b}, *}$ \\ ${ }^{a}$ Brookhaven National Laboratory, Upton, New York 11973, USA \\ ${ }^{b}$ The Fontana Corrosion Center, The Ohio State University, Columbus, Ohio 43210, USA
}

\begin{abstract}
In situ X-ray adsorption near-edge structure (XANES) has been used to investigate the formation of chromate conversion coatings on pure Al, commercial Al alloys (AA 1100, AA2024, and AA7075), and a series of binary Al-Cu alloys. The method employed cells designed to determine the growth of the total chromium [Cr(total)] and hexavalent chromate [Cr(VI)] in the chromate conversion coating $(\mathrm{CCC})$ as a function of exposure time to a chromate solution. Three sets of data were obtained, where $(i)$ the Al was exposed to only a limited amount of solution; (ii) the chromate solution was excluded after short periods of repeated exposures to the solution; and (iii) the Al was exposed continuously to the chromate solution. All the results showed a very rapid initial growth within the first seconds, followed by a continued increase in thickness for exposures up to $1 \mathrm{~h}$. Measurements with Al-Cu binary alloys demonstrated that the difference observed in AA2024 and AA1100 may not be due to Cu alloying. The proportion of $\mathrm{Cr}(\mathrm{VI})$ in the coatings becomes approximately constant after $180 \mathrm{~s}$ of exposure for all the specimens examined, even though the coatings continued to grow.

(C) 2005 The Electrochemical Society. [DOI: 10.1149/1.2041027] All rights reserved.
\end{abstract}

Manuscript submitted February 18, 2005; revised manuscript received June 15, 2005. Available electronically September 21, 2005.

Considerable efforts have been made in the understanding of the formation and properties of chromate conversion coatings (CCCs) because of the excellent protection afforded by the coating as well as its ease of application. Studies have also been carried out to understand the role of the coating in protecting surfaces as a basis for developing replacements for CCCs because of its toxicity. Very few in situ CCC measurements have been carried out. An example of open-circuit potential measurements is given by Campestrini et al. ${ }^{1}$ Goeminne et al. ${ }^{2}$ and Vuillemin et al. ${ }^{3}$ used electrochemical reduction of chromate on graphite electrodes to monitor chromate that did not react at the $\mathrm{Al}$ surface. The former investigators used a rotating ring-disk method with an $\mathrm{Al}$ alloy as the disk and graphite ring. ${ }^{2}$ The latter investigators employed a flow system with a graphite electrode downstream to an Al alloy to study CCC growth following laser removal of a thin mask that initially protected the Al. They also employed a quartz crystal microbalance on which the alloy film was sputtered, and coupled the mass variations with chromate consumption. $^{3}$

X-ray adsorption offers a powerful method for the in situ study of the kinetics of chemical changes taking place at surfaces, by monitoring the growth and dissolution of the films. ${ }^{3-12} \mathrm{X}$-ray adsorption near-edge structure (XANES) has been used to study the products of reactions of chromate conversion coatings (CCC) adhering to $\mathrm{Al}$ surfaces, and the behavior of these products with time and exposure to solutions. ${ }^{4-13} \mathrm{CCC}$ are made up of $\mathrm{Cr}(\mathrm{III})$ and $\mathrm{Cr}(\mathrm{VI})$ species such as in $\mathrm{CrO}_{4}^{2-}$; the latter is believed to be responsible for CCC's ability to protect scratches on a metal surface from undergoing further electrochemical degradation. A factor that assists in the determination of $\mathrm{Cr}$ speciation is a distinct pre-edge peak at $5993 \mathrm{eV}$ in the XANES spectrum when hexavalent chromium $\mathrm{Cr}(\mathrm{VI})$ is present. In addition, the ratio of height above the edge arising from all chromium species present $[\mathrm{Cr}($ total $)]$ to the pre-edge height [only $\mathrm{Cr}(\mathrm{VI})$ ] provides a quantitative measure of $\mathrm{Cr}(\mathrm{VI})$ content in the CCC. However, XANES measurements of CCC have generally been made ex situ.

In this study, we introduce designs of cells that allow monitoring of a specimen surface exposed to a chromate solution without being removed from the aqueous environment. We present data on aluminum and its alloys $(i)$ when exposed to a limited volume of solution; (ii) when subjected to repeated exposure to the chromate solution; and (iii) when continuously exposed to the CCC solution. From

\footnotetext{
** Electrochemical Society Fellow.

* Electrochemical Society Active Member.
}

these findings, we discuss the kinetics of the CCC formation and the effect of $\mathrm{Cu}$ additions.

\section{Experimental}

One set of specimens used in this study were rectangular pieces of pure $\mathrm{Al}$ (99.999\% purity), AA $1100-\mathrm{O}$, AA 2024-T3, AA 7075T6, and binary high purity $\mathrm{Al}-\mathrm{Cu}$ solid solution alloys $(\mathrm{Cu}$ contents: $0.2,1,2$, and $4 \mathrm{wt} \%$ ), cut to dimensions of ca. $12 \times 12 \times 1 \mathrm{~mm}$ Table I lists the specifications of composition for the commercial alloys. The binary $\mathrm{Al}-\mathrm{Cu}$ alloys were solution annealed at $535^{\circ} \mathrm{C}$ and quenched in water; the alloys were then aged at $150^{\circ} \mathrm{C}$ for a period of $24 \mathrm{~h}$. No microstructural analysis of the specimen surfaces was done. The surfaces were wet ground on a 600-grit abrasive paper. The specimens then were immersed in $8 \mathrm{wt} \% \mathrm{KOH}$ for $5 \mathrm{~min}$, rinsed in distilled water, immersed in $50 \mathrm{wt} \% \mathrm{HNO}_{3}$ for $5 \mathrm{~min}$, and finally rinsed thoroughly in distilled water. The samples were then mounted on a plastic support. All specimens were prepared less than $1 \mathrm{~h}$ before the measurements. Commercial Alodine 1200 (Parker Amchen, Michigan) was used at a concentration of $7.5 \mathrm{~g} \mathrm{~L}^{-1}$ and at room temperature.

We developed a novel cell similar in principle to that used by Toney et al. ${ }^{14}$ in which one side of the specimen is covered with a plastic film transparent to X-rays separated by a thin, $\sim 10 \mu \mathrm{m}$ liquid layer, ${ }^{15}$ as schematically shown in Fig. 1 . The cell is completely sealed except for a tube connected to a reservoir of a chromate solution. By lifting the reservoir, hydrostatic pressure in the cell is increased so the solution flows into the cell and inflates the membrane (Fig. 1a). Suction or lowering the reservoir causes a fall in pressure in the cell, so that the solution is drained off and the membrane drawn up against the specimen surface excluding all but a very thin film of liquid thereby suppresses the surface reaction (Fig. 1b). Expelling the solution was ensured by pressing the membrane against the sample immediately after deflation. XANES measurements were then made. Using this approach, exposure of the specimen surface to a bulk chromate solution can be interrupted to permit XANES measurements. Repeated exposure-interruptionmeasurement cycles permit detailed characterizations of coating growth to be carried out.

This cell was also used when the chromate solution was not completely drained from the cell, leaving a thin layer of solution trapped in contact with only the specimen surfaces. Trapping the chromate was achieved by having a sample with sharp edges, against which the membrane formed a seal. Changes in the chromium chemistry with increasing exposure time were monitored as the chromate reacted with the Al sample. 
Table I. Specifications of composition for commercial Al Alloys (from Ref. 25).

\begin{tabular}{cllllllr}
$\begin{array}{c}\text { AA } \\
\text { number }\end{array}$ & \multicolumn{1}{c}{$\mathrm{Si}$} & $\mathrm{Fe}$ & $\mathrm{Cu}$ & \multicolumn{1}{c}{$\mathrm{Mn}$} & $\mathrm{Mg}$ & $\mathrm{Cr}$ & $\mathrm{Zn}$ \\
\hline 1100 & $1.0(\mathrm{Si}+\mathrm{Fe})$ & & $0.05-0.20$ & 0.05 & & & 0.10 \\
2024 & 0.50 & 0.50 & $3.8-4.9$ & $0.30-0.9$ & $1.2-1.8$ & 0.10 & 0.25 \\
7075 & 0.40 & 0.50 & $1.2-2.0$ & 0.30 & $2.1-2.9$ & $0.18-0.28$ & $5.1-6.1$
\end{tabular}

The growth of the CCC on the specimen surfaces during continuous exposure to the chromate solution also was monitored in a different cell, somewhat similar to that described previously. ${ }^{4}$ Foil of the metal or alloy (ca. $60 \mu \mathrm{m}$ thick) was mounted over a 15 $\times 5 \mathrm{~mm}$ window cut into one side of a small, rectangular $60 \mathrm{ml}$ plastic tissue culture flask so that one side of the foil could be exposed to the solution. The foils were annealed at $400^{\circ} \mathrm{C}$ and water quenched after rolling and exposed to $8 \mathrm{wt} \% \mathrm{KOH}$ for $5 \mathrm{~min}$, rinsed in distilled water, immersed in $50 \mathrm{wt} \% \mathrm{HNO}_{3}$ for $5 \mathrm{~min}$, and finally rinsed thoroughly in distilled water.

The XANES spectra were made on Beamline X-10C at the National Synchrotron Light Source (Brookhaven National Laboratory). The specimen surface was oriented at an angle of $45^{\circ}$ to the incident beam, which was approximately $5 \times 0.5 \mathrm{~mm}$. A solid-state detector was positioned at $90^{\circ}$ to the incident beam to collect fluorescence radiation from the sample or in two sets of experiments, from the sample and chromate solution. The intensity of the fluorescence was normalized relative to the incident beam. Details of similar experimental procedure for the XANES studies are given elsewhere. ${ }^{4-7}$ In general, the time to acquire each spectrum was kept to a minimum. The number of points acquired in each spectrum was kept to a minimum, and the integration time of each point was set at $1 \mathrm{~s}$.

\section{Results and Discussion}

The in situ investigation of the CCC formation kinetics is described in three parts. First, we describe the reactions taking place with a limited but measurable amount of chromate solution to determine the kinetics of reaction and any subsequent chemical changes once the chromate in solution had reacted to form a conversion coating. Measurements were then made repeatedly exposing Al surfaces to the bulk chromate solution for brief periods of time, followed by excluding the chromate solution from contact with the $\mathrm{Al}$, leaving a very thin layer of reacted solution between the surface and the plastic membrane. Finally, the growth of a CCC was monitored while it remained in contact with bulk chromate solution, to ensure that any significant aging of the surface did not dramatically change the growth kinetics when the chromate solution was excluded during the XANES measurements.

Reaction with a limited volume of solution.-Measurements were carried out to show that the chromium speciation reached a final state when a limited volume of the chromating solution was trapped between the membrane and an Al surface. In the example given an $\mathrm{Al}-0.2 \% \mathrm{Cu}$ sample was used. Continuous XANES measurements were made which monitored the changes in both electrolyte and a CCC formed during exposure. This was achieved by confining the chromate solution between the sample and the plastic membrane to a limited volume. Each XANES scan took and was repeated every $78 \mathrm{~s}$. The thickness of the solution layer was too thin to be measured with available techniques, although curvature of the membrane was apparent. If too small a layer of solution was trapped, the conversion of the chromate occurred in less than $78 \mathrm{~s}$ and was too rapid to monitor. If thick solution layers were used then the chromate in solution would mask the reactions on the surface and only changes in the solution would be seen. Calculations of the effects of solution thickness were therefore carried out.

The energy dispersive X-ray fluorescence intensity of chromium as a function of the thickness of a layer of solution was calculated based on the composition of the chromating solution employing a computer program, NRLXRF. The program uses a fundamental pa- rameters method that takes into account the energy of the beam and the effects of absorption due to filters and multielement samples. ${ }^{16}$ An X-ray beam energy of $6 \mathrm{keV}$ was used and the composition of the Alodine solution was taken as $30 \mathrm{mM} \mathrm{CrO}_{3}, 14.5 \mathrm{mM} \mathrm{NaF}$, $15 \mathrm{mM} \mathrm{KBF}_{4}, 2 \mathrm{mM} \mathrm{K}_{2} \mathrm{ZrF}_{6}$, and $3 \mathrm{mM} \mathrm{K}_{3} \mathrm{Fe}(\mathrm{CN})_{6}$. Calculations showed that the absorption was dominated by the oxygen in the water rather than the chromium or heavier elements in the solution.

Curve A in Fig. 2 shows the predicted $\mathrm{Cr}$ fluorescence intensities as a function of solution thickness. The $\mathrm{Cr}$ intensity varies linearly with thickness below about $60 \mu \mathrm{m}$. Between 60 and $140 \mu \mathrm{m}$ the incoming and scattered X-rays are absorbed within the solution, and the intensity of the $\mathrm{Cr}$ signal increases progressively less rapidly with thickness, eventually reaching a constant value above about $140 \mu \mathrm{m}$, an effective infinite solution thickness. If the thickness of solution trapped between the membrane and the substrate was above $140 \mu \mathrm{m}$, the $\mathrm{Cr}$ signal would decrease as the formation of the CCC extracted chromate from the solution. No signal would be observed from the CCC because of absorption of the X-rays in the solution. With solution thickness above about $60 \mu \mathrm{m}$, detectable changes in both the solution and at the specimen surface should be observed.

Figure 3a shows a series of in situ repeated XANES spectra for AA 1100 with trapped chromate solution. An important feature of the results was the presence of an isosbestic point at energy of $6012 \mathrm{eV}$, indicating that there was no significant change in the amount of $\mathrm{Cr}$ detected. If there was absorption by the water the detected signal from the $\mathrm{Cr}$ would decrease as the $\mathrm{Cr}$ was extracted from the solution and collected in the CCC as it was converted. The absence of change is indicative that the solution thickness was less than $60 \mu \mathrm{m}$. The constant amount of $\mathrm{Cr}$ also indicated that there was no leakage into or out of the trapped volume. An important feature of the measurements was very little change in the spectra after 390 and $468 \mathrm{~s}$ and for subsequent scans, which indicated that reactions had reached completion. Xia et al. have shown that there is an equilibrium concentration of chromate in the solution in contact with simulated CCC compounds that varies with $\mathrm{pH} .{ }^{17}$ At $\mathrm{pH}$ values below 4, the chromate concentration in solution was found to be close to zero, suggesting all the chromate was extracted from solu-

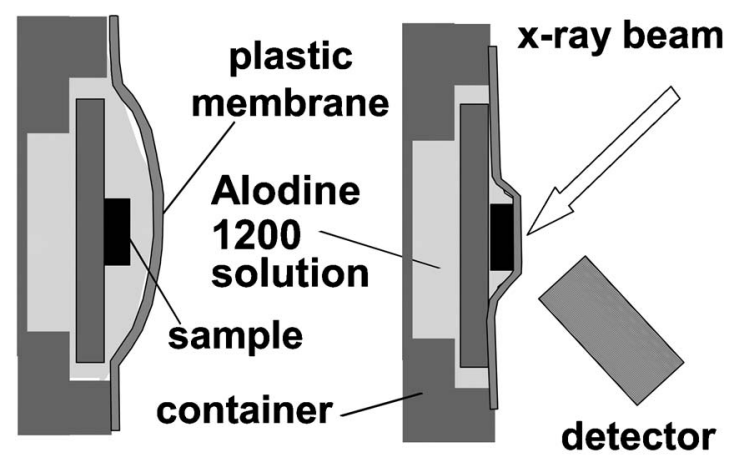

(a) inflated

(b) deflated

Figure 1. Schematic of the cell used for the in situ study of the formation of chromate conversion coatings. The cell is shown (a) with a covering membrane inflated to allow contact with the bulk chromate solution, and (b) with the membrane deflated displacing the solution and pressing in close contact with the specimen surface. 


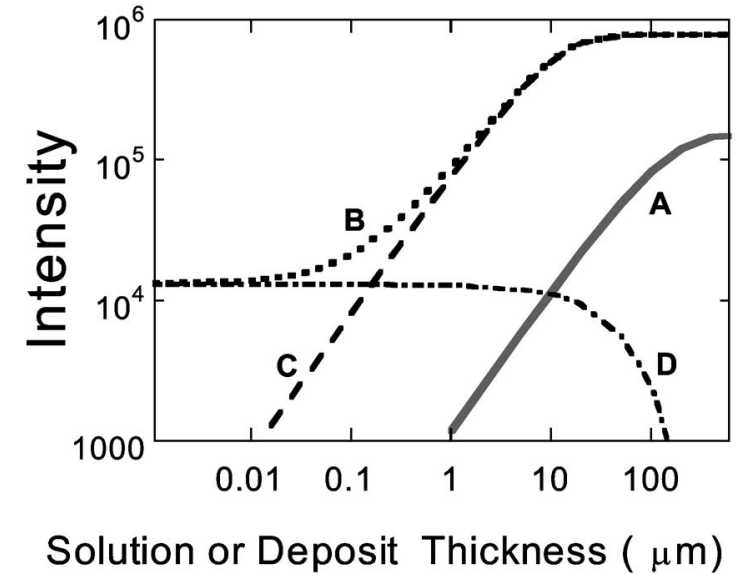

Figure 2. Calculated fluorescence intensities. Curve A: the intensity as a function of the thickness of chromate solution. Curve B: the intensity emitted from the back of an $\mathrm{Al}$ foil, as a function of the chromate conversion coating thickness formed on the front of the foil in contact with the chromate solution. The intensity of curve B is the sum of the intensity contribution from the coating itself, curve $\mathrm{C}$, and the intensity from only the solution, curve D, which is modified because of the thickness of the coating.

tion and incorporated into the CCC. The data in Fig. 3a are therefore consistent with the formation of a stable CCC by reactions that fully extract chromate from the small volume of trapped solution. At the end of the reaction the fraction of $\mathrm{Cr}(\mathrm{VI})$ ions was ca. 33\%.

The results in Fig. 3a can be modeled by taking relative proportions of the spectra for the chromating solution as represented by the first spectrum recorded, and the spectrum for the CCC, represented by the spectra after $390 \mathrm{~s}$. Figure $3 \mathrm{~b}$ presents the modeled results. The figure caption gives the ratios of those of the solution and the $\mathrm{CCC}$ used in the calculation. The growth of the CCC derived from the modeling is shown in Fig. 4, which demonstrates that the CCC formed in a restricted volume of solution is compositionally stable once the formation reaction is complete. In these experiments, the initial fraction of $\mathrm{Cr}(\mathrm{VI})$ within the $\mathrm{CCC}$ was masked by chromate in solution, which dominated the observed spectra at short exposure times. This was not the case when the plastic film was completely deflated and minimal solution was trapped between the film and the sample, as is described below for repetitive exposures of the sample to bulk chromating solution.

Interrupted exposures to chromating solution.- Using the cell illustrated in Fig. 1, we were able to grow a CCC in steps using the exposure-interruption-measurement approach described in the Experimental section. The time of exposure to the chromate solution ranged from 2 to $300 \mathrm{~s}$ to enable monitoring of rapid initial changes in the CCC, as well as the relatively slower subsequent exposures. Figure 5a presents a series of in situ XANES spectra of the stepwise growth of the CCC film on AA 2024-T3. After each exposure period, the surface reaction was suppressed by deflating the membrane and expelling the solution from the region between the sample and the plastic film. The height of the pre-edge peak seen (at $5993 \mathrm{eV}$ ) was a measure of the amount of $\mathrm{Cr}(\mathrm{VI})$ ions present in the $\mathrm{CCC}$, while that above the absorption edge represents the total amount of all $\mathrm{Cr}$ species. The height above the edge was not well defined, nor were measurements made well above the edge to better define the height as is normally done, because the time during the measurements was kept to a minimum. The analysis of Fig. 3 showed that the two major Cr-containing constituents, the chromating solution and in particular that of the $\mathrm{CCC}$, could be quantified at the isosbestic point. Hence, the total amount of $\mathrm{Cr}$ could be measured by the height at the isosbestic point and correcting it to the edge height. This approach required that there be only two types of $\mathrm{Cr}$ species in the film. The isosbestic point occurs at a higher energy of $6026 \mathrm{eV}$
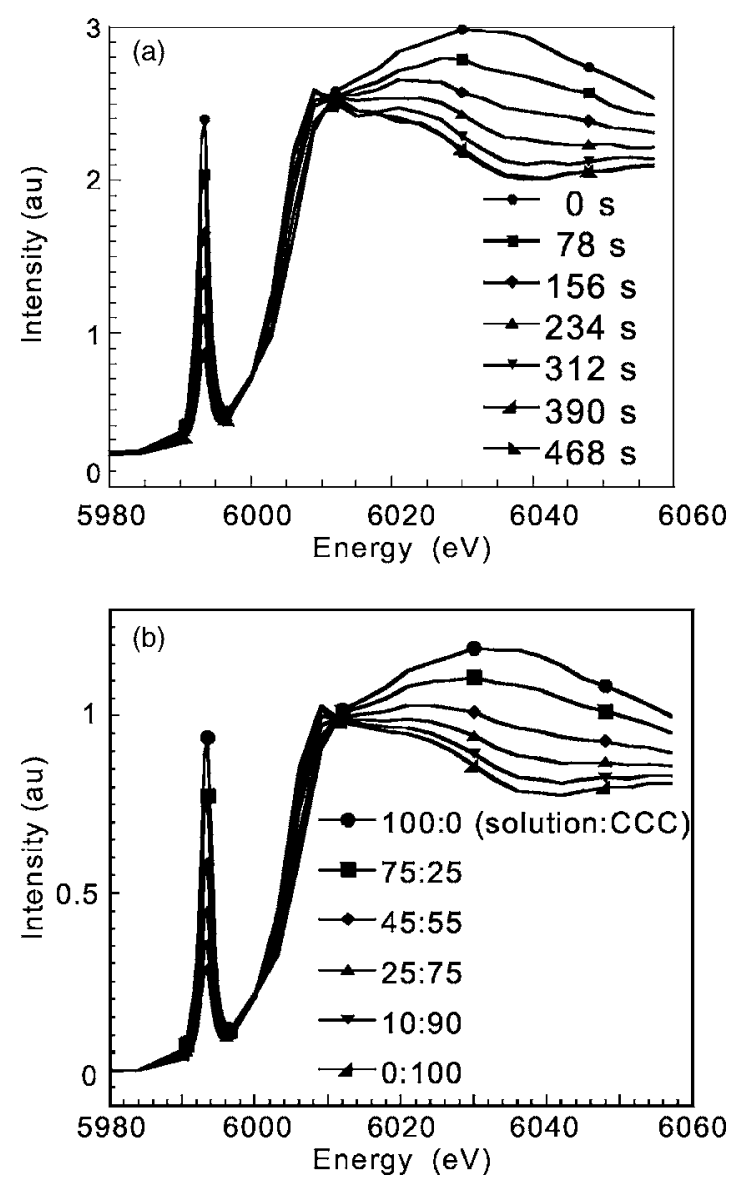

Figure 3. (a) Changes in XANES with time as a restricted volume of chromate solution reacted with an AA1100 surface. (b) Simulation of the results by summing fractions of the initial spectrum for the unreacted solution and the final spectrum for the conversion coating.

rather than $6012 \mathrm{eV}$ for solutions of $\mathrm{Cr}(\mathrm{III})$ and $\mathrm{Cr}(\mathrm{VI}),{ }^{13}$ indicating the $\mathrm{Cr}(\mathrm{III})$ in the CCC has a different near-edge structure, which may change with time as the $\mathrm{Cr}$ (III) surface films are not normally stable, well-structured compounds. ${ }^{4-7,9-13}$ The low integration time of $1 \mathrm{~s}$ for each point and the low amount of $\mathrm{Cr}$ in the CCC also increased the scatter in the XANES data. This reduced the accuracy with which the height of the pre-edge $\mathrm{Cr}(\mathrm{VI})$ peak could be determined. In view of the low signal-to-noise ratio, the greatest uncertainty in the relative $\mathrm{Cr}(\mathrm{VI})$ content exists for data collected in the first few exposures. With increasing thickness of the $\mathrm{CCC}$, the signal-to-noise ratio improved, and the uncertainty associated with the relative $\mathrm{Cr}(\mathrm{VI})$ content determination was reduced. These factors lead to a reduced confidence in the estimation of the fraction of $\mathrm{Cr}(\mathrm{VI})$ of about $\pm 20 \%$ in an effort to monitor the in situ kinetics of growth of the CCC. Nonetheless, the trends in the behavior with time are clear, even though the absolute values may be uncertain. Ex situ XANES determinations of the $\mathrm{Cr}$ ration have been reported and offer more accurate measures of the $\mathrm{Cr}(\mathrm{VI})$ ratios. ${ }^{9-13}$ The scatter in the results is seen in Fig. $5 \mathrm{~b}$ to be very high at the start, but after $20 \mathrm{~s}$ of total repeated exposures to the bulk solution, the trends in the growth behavior of the $\mathrm{CCC}$ and $\mathrm{Cr}(\mathrm{VI})$ are clearly distinguishable, as is the decrease in the $\mathrm{Cr}(\mathrm{VI})$ content with increasing CCC thickness.

Repeated scans while the plastic film was deflated showed reproducibility, within the scatter of the results, indicating that the reactions were complete during the first scan, no compositional changes took place due to solution reaction or aging of the $\mathrm{CCC}$, and there was no leakage of solution into the region between the sample and the membrane. These findings are consistent with the results in Fig. 


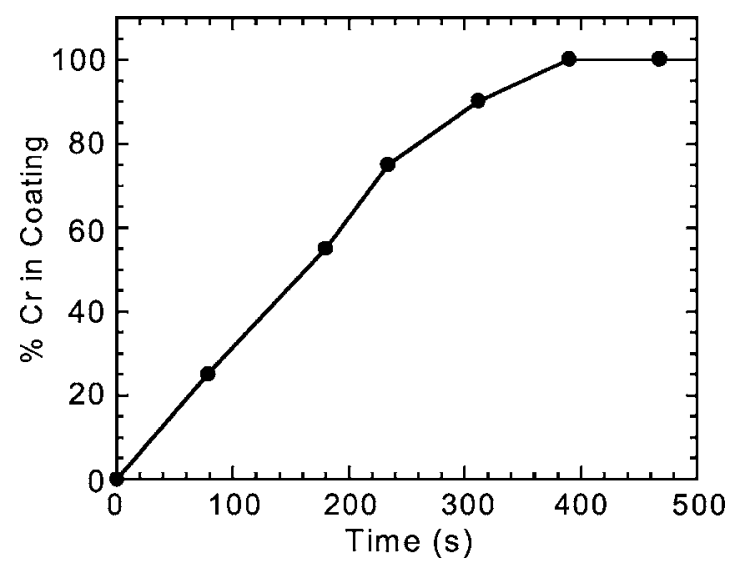

Figure 4. Growth of chromate coating in a restricted volume of chromate solution. Data taken from Fig. 3b.

3 which show that, with a comparatively large volume of trapped solution, once the reaction reaches completion there are no further observable changes. They are also consistent with the results in Fig. 4 which show a sharp cutoff in CCC growth once the solution has been depleted of chromate.

The heights of the edge due to $\mathrm{Cr}$ (total) and the pre-edge peak due to $\mathrm{Cr}(\mathrm{VI})$ and for AA2024-T3 are plotted against immersion time in Fig. 5b. Also shown are the trends for the $\mathrm{Cr}(\mathrm{VI}) / \mathrm{Cr}($ total $)$ ratio in the CCC. After the first exposure, even though just $3 \mathrm{~s}$ in duration, there was a distinct step increase in $\mathrm{Cr}(\mathrm{VI})$ and $\mathrm{Cr}$ (total), indicating a very rapid initial reaction rate. Very rapid initial CCC deposition rates have also been reported by other investigators ${ }^{13,18-20}$ and have necessitated modification of solutions in order to study the earliest stages of the CCC formation. ${ }^{18,19}$ Following the initial jump, the amounts of $\mathrm{Cr}(\mathrm{VI})$ and $\mathrm{Cr}$ (total) then increased steadily with immersion time, indicating continuous growth of the CCC layer during all consecutive exposures. The rates for AA2024-T3 decline with the buildup of the CCC layer, following a rate with time raised to a power distinctly smaller than one-half found by other investigators. The ratio of $\mathrm{Cr}(\mathrm{VI}) / \mathrm{Cr}$ (total) was initially high, and then decreased from close to $60 \%$ to about $40 \%$ after $100 \mathrm{~s}$. The proportion of $\mathrm{Cr}(\mathrm{VI})$ in the $\mathrm{CCC}$ becomes constant after $180 \mathrm{~s}$, even though the $\mathrm{CCC}$ continued to grow.

Figure 6 presents the changes in the amounts of $\mathrm{Cr}(\mathrm{VI}), \mathrm{Cr}($ total), and the ratio of $\mathrm{Cr}(\mathrm{VI}) / \mathrm{Cr}$ (total) in a CCC formed on AA1100 up to an exposure time of $600 \mathrm{~s}$. The $\mathrm{Cr}(\mathrm{VI})$ fraction in the $\mathrm{CCC}$ showed similar behavior to AA2024-T3, with a very rapid decrease with time as the CCC thickened. The amounts of $\mathrm{Cr}(\mathrm{VI})$ and $\mathrm{Cr}$ (total) again showed the very rapid initial growth rate, but continued to increase with time at a steady rate compared with that of the AA 2024-T3 (Fig. 5), where the rate continued to decrease. Linear in situ growth of a chromate-phosphate film on a $99.5 \% \mathrm{Al}$ surface in a $0.03 \mathrm{M} \mathrm{CrO}_{3}$ solution containing $\sim 50 \mathrm{mM} \mathrm{HF}$ has been observed using a ring electrode, but the growth behavior varied with fluoride contents. ${ }^{2}$ Ex situ Auger analysis with a similar alloy and solutions but static conditions also showed a linear behavior. ${ }^{1}$

Measurements were also carried out on AA 7075, but the chromium in the alloy dominated the measurements and prevented a detailed analysis of the CCC.

The initial rapid growth of the CCC has been attributed to the role of cathodic sites on the surface generally due to alloying element-rich intermetallic particles, which have been identified as sites that nucleate the CCC. ${ }^{18,21,22}$ McGovern et al. ${ }^{21}$ concluded that the deposition rate on $\mathrm{Mg}$-containing intermetallics slowed with increased $\mathrm{Cu}$ content due to adsorption of cyanide on the $\mathrm{Cu}$-rich sites. The cyanide is derived from potassium ferricyanide that is added to commercial CCC bath formulations to accelerate the coating deposition process on aluminum. However, McGovern's findings suggest
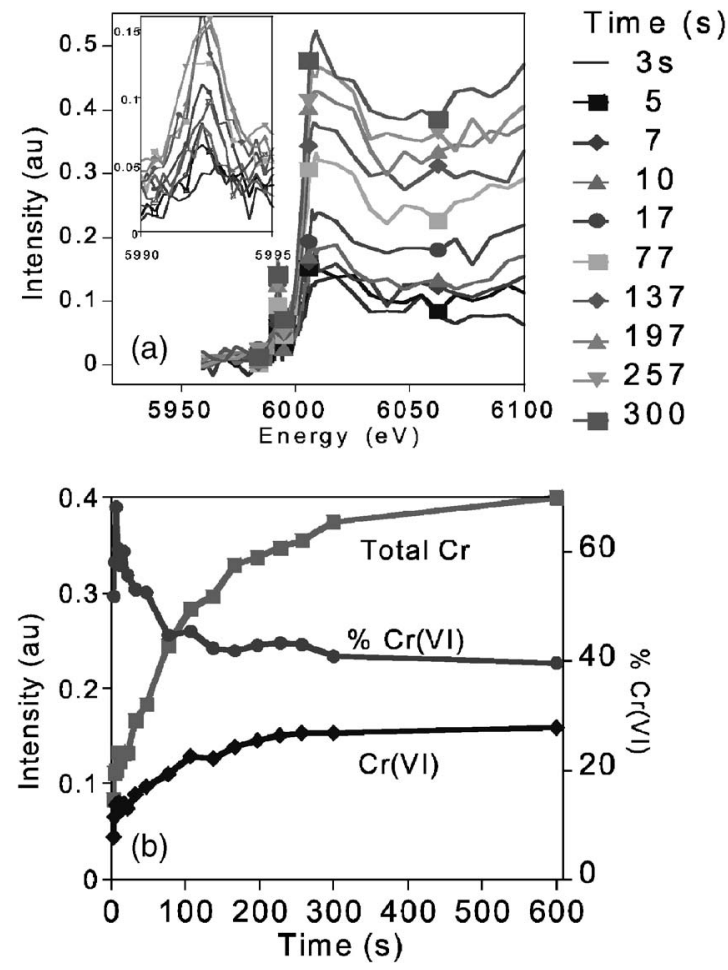

Figure 5. (a) XANES of the conversion coating on AA2024 for increasing exposures times to bulk chromate solution. (b) Variations in intensity of the chromate $\mathrm{Cr}(\mathrm{VI})$, the total $\mathrm{Cr}$, and the $\mathrm{Cr}(\mathrm{VI})$ fraction with time.

an unintended consequence on $\mathrm{CCC}$ formation for Cr-containing $\mathrm{Al}$ alloys. These explanations offer a possible cause for the marked decrease in CCC deposition rate on AA2024-T3 compared to AA1100. If significant differences were caused by cathodic sites associated with $\mathrm{Cu}$ in the alloy, differences should be seen with Al-Cu binary alloys containing 0.2 to $4 \% \mathrm{Cu}$. The results of these repeated exposures tests using a membrane cell are shown in Fig. 7a and $\mathrm{b}$.

The $\mathrm{CCC}$ formation behavior on the Al-Cu binary alloys differed from that on the commercial alloys in several ways. Based on the variation in total $\mathrm{Cr}$ as a function of immersion time, $\mathrm{CCC}$ formation rate showed a plateau after an initial episode of rapid growth. The length of the plateau increased with $\mathrm{Cu}$ content from 140 to $180 \mathrm{~s}$ for 0.2 and $4.0 \% \mathrm{Cu}$, respectively. Pure $\mathrm{Al}$ showed only an indication of a plateau up to around $20 \mathrm{~s}$. After the plateau, rates again

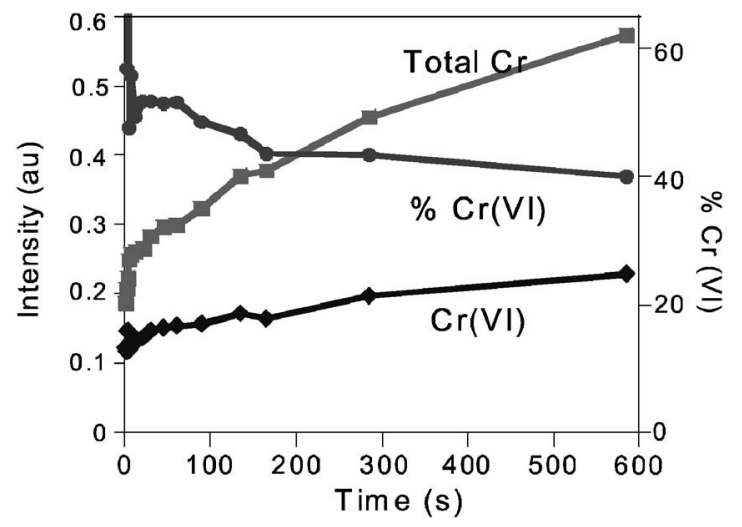

Figure 6. Variations in intensity of chromate $\mathrm{Cr}(\mathrm{VI})$, total $\mathrm{Cr}$, and the $\mathrm{Cr}(\mathrm{VI})$ fraction for the conversion coating on AA1100 with increasing exposure time. 

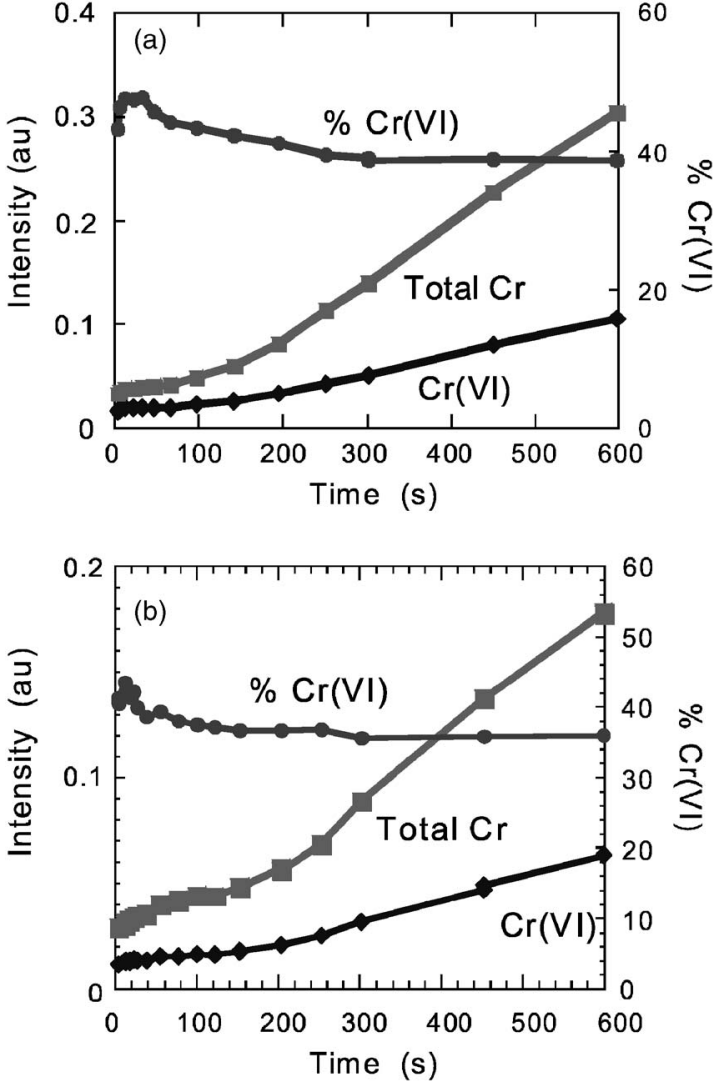

Figure 7. Variations in the intensity of $\mathrm{Cr}(\mathrm{VI})$, total $\mathrm{Cr}$, and the $\mathrm{Cr}(\mathrm{VI})$ fraction with time of exposure to bulk chromate solution for (a) $\mathrm{Al}-0.2 \% \mathrm{Cu}$, and (b) $\mathrm{Al}-4 \% \mathrm{Cu}$.

increased, being approximately constant up to $600 \mathrm{~s}$. The ratios of $\mathrm{Cr}(\mathrm{VI}) / \mathrm{Cr}$ (total) in $\mathrm{CCCs}$ formed on the $\mathrm{Al}-\mathrm{Cu}$ binary alloys showed less variation with coating time than the commercial alloys, as shown by a set of measurements in Fig. 8.

Hence, other than the delay after the initial deposition of the $\mathrm{CCC}$, the additions of $\mathrm{Cu}$ did not show any trends. The major difference in growth behavior was shown by AA2024-T3. One possible cause is the greater concentration of $\mathrm{Cu}$-rich second-phase particles in this alloy, and the role of these particles in the growth of the CCC requires further study.

Continuous exposures in contact with chromate solution.- The experiments with the repeated exposures in the membrane cell indicated that the thickness of the CCC would increase continually with time, the possible exception to this being AA2024-T3, where the growth rates at longer immersion times decreased nearly to zero. Ex situ measurements by Kendig et al. ${ }^{12}$ found that the CCC thickness reached a constant value after about $5 \mathrm{~min}$ immersion. These samples were washed and dried following a timed exposure in chromate solution. A similar behavior was seen by Katzman et al. ${ }^{23}$ for AA1100. One possible cause for the difference in the growth behavior in our result where the film continues to grow may be related to aging of the coating when the bulk chromate solution was excluded. Alternatively, the adherence of the film may change and even though the film continued to grow, the outer layers of the film may wash off upon rinsing in water, leaving an adherent inner layer. Measurements were therefore carried out to monitor the in situ growth of the $\mathrm{CCC}$ without restricting the access to the chromate solution, and to remove any possible effects of aging.

The measurements were made using a thin, $60 \mu \mathrm{m}$ alloy foil window covering a cutout in a plastic container holding the chromate solution. The X-rays penetrated through the foil, then through

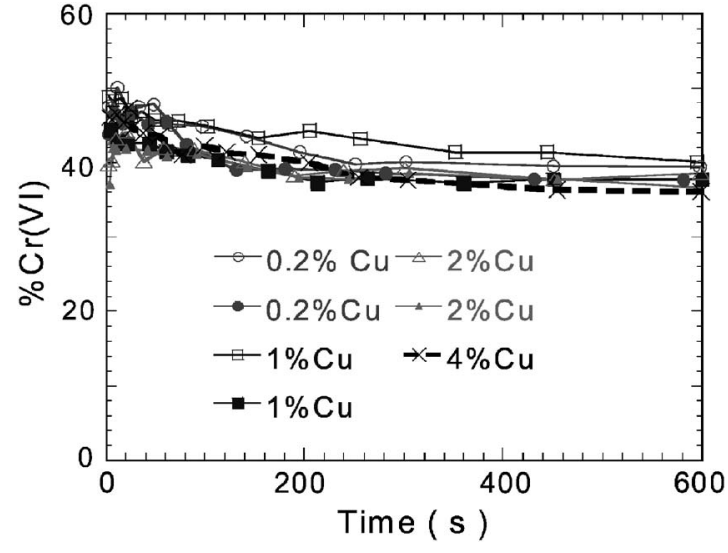

Figure 8. Variations in the intensity of the $\mathrm{Cr}(\mathrm{VI})$ fraction with time of exposure to bulk chromate solution for $\mathrm{Al}-\mathrm{Cu}$ alloys.

the CCC building up on the foil, and into the chromate solution. Because of the geometry and the $\mathrm{Cr}(\mathrm{VI})$ in solution, a quantitative analysis of the $\mathrm{Cr}$ speciation in the CCC was not attempted. Nonetheless, qualitative indications of the growth of the CCC were possible.

In situ XANES spectra for a continuously growing $\mathrm{CCC}$ are shown in Fig. 9a for an $\mathrm{Al}-0.2 \% \mathrm{Cu}$ foil. The spectra were measured every $225 \mathrm{~s}$ for an hour starting after a $30 \mathrm{~s}$ exposure to the solution. In Fig. 9a, the spectrum with the lowest intensity, depicted by white circles, corresponds to the first scan. Also shown are the consecutive
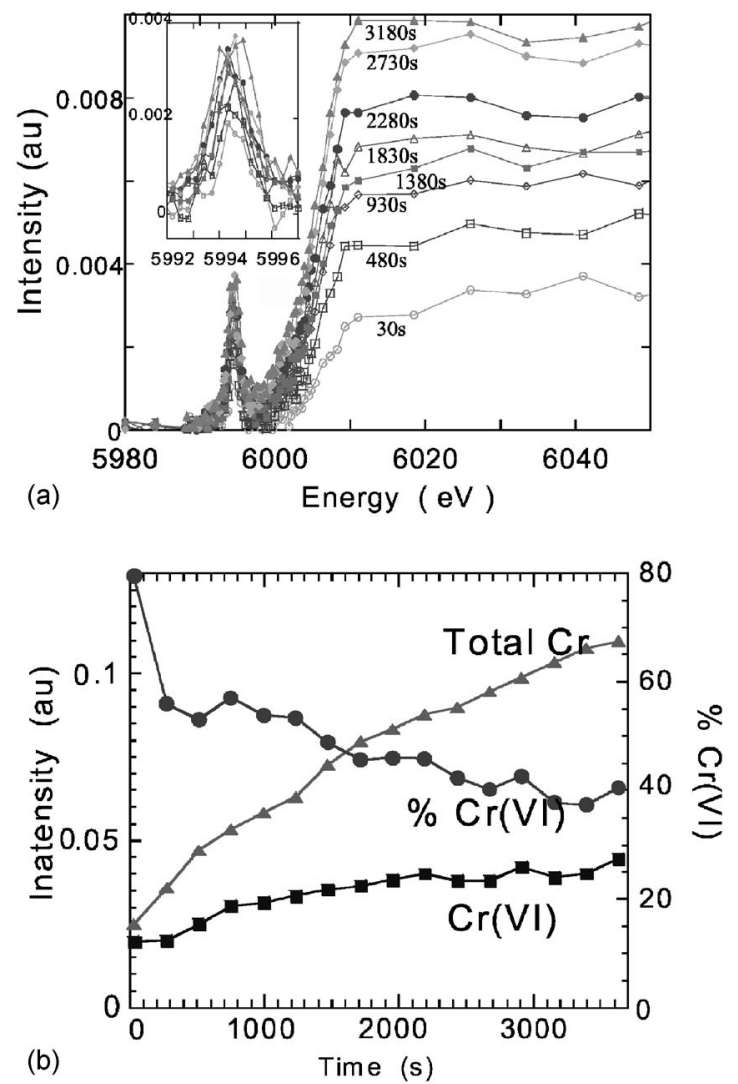

Figure 9. (a) XANES acquired during formation of a conversion coating on Al- $0.2 \% \mathrm{Cu}$ foil continuously exposed to the chromate solution. Timing was started upon adding the chromate solution. Times on each curve indicate when the scans were started. (b) Variations in intensity of the chromate $\mathrm{Cr}(\mathrm{VI})$, the total $\mathrm{Cr}$, and the $\mathrm{Cr}(\mathrm{VI})$ fraction with time. 
spectra measured every $450 \mathrm{~s}$, which show an increase of intensity with increasing immersion time. Figure $9 \mathrm{~b}$ shows the changes in the intensity of the $\mathrm{Cr}$ (total) and $\mathrm{Cr}(\mathrm{VI})$. The first XANES scan indicated that the major fraction of the $\mathrm{Cr}$ (total) was due to $\mathrm{Cr}(\mathrm{VI})$ from the chromate solution. As the CCC grew, the total $\mathrm{Cr}$ increased and the fraction of $\mathrm{Cr}(\mathrm{VI})$ recorded decreased to levels observed using the other methods of monitoring CCC deposits after about $3000 \mathrm{~s}$. The growth rate appeared linear on the first $500 \mathrm{~s}$ and decreased by a factor of about 2 toward the end of the test.

The film did not reach a constant thickness after $5 \mathrm{~min}$, but continued to increase for the $60 \mathrm{~min}$ period of the measurement and excluded any dramatic aging effects during the experiments where the sample was repeatedly exposed to bulk chromate that enabled the film to grow continuously. Nevertheless, minor effects resulting from the exclusion of the chromate solution cannot be ruled out. Changes in the nature of the film and the growth processes of the thick CCC are probably responsible for the lack of adherence and the loss of the outer part of the film on rinsing. The object of the present study, to demonstrate the application of the $\mathrm{Al}$ foil technique to study the growth of conversion layers, was achieved, but further work should also be carried out with AA2024-T3 as this alloy did show changes indicative of comparatively limited CCC formation.

The NRLXRF calculation of the expected fluorescence emanating from the chromate solution and the $\mathrm{CCC}$ as a function of its thickness for the foil geometry are included in Fig. 2. An atomic ratio of $\mathrm{Cr}$ to $\mathrm{O}$ in the $\mathrm{CCC}$ of 3 with a density of $2.5 \mathrm{~g} / \mathrm{cm}^{3}$ was used in the calculations. Three curves relate to this calculation. The $\mathrm{Cr}$ fluorescence from the CCC, the solution, and the sum of these two intensities which represent the detected signal. The unity slope in logarithmic plot for the CCC alone shows that the $\mathrm{Cr}$ fluorescence signal increases in proportion to its thickness up to $7 \mu \mathrm{m}$. At greater thicknesses the self-absorption within the CCC slows the increase and an infinite thickness is reached above about $30 \mu \mathrm{m}$. The $\mathrm{Cr}$ signal only from the solution remains constant up to a CCC thickness of $7 \mu \mathrm{m}$, virtually unaffected by X-ray absorption by the CCC. Above this thickness the signal rapidly decreases because of the absorption in the CCC. The summed fluorescence curve shows that the solution only dominates until a CCC thickness of $0.01 \mu \mathrm{m}$ is reached. Between 0.01 and $1 \mu \mathrm{m}$ both the solution and the CCC contribute, whereas above $2 \mu \mathrm{m}$ the CCC fluorescence dominates.

The calculated intensities emitted in Fig. 2 may be used as a template to estimate the possible thickness range of the deposit. Two critical thicknesses of the CCC are indicated in Fig. 2. The first is around $0.01 \mu \mathrm{m}$, when the $\mathrm{CCC}$ begins to contribute to the predicted $\mathrm{Cr}$ intensity. For a very thin CCC the intensity is dominated by emission from the $\mathrm{Cr}$ in solution and would be $100 \% \mathrm{Cr}(\mathrm{VI})$. From the start of the experiment both the total $\mathrm{Cr}$ increased and the fraction of $\mathrm{Cr}(\mathrm{VI})$ decreased, demonstrating (based on the calculations in Fig. 2) that the CCC grew to a thickness greater than $0.01 \mu \mathrm{m}$ within the first $30 \mathrm{~s}$. Had the CCC thickness been smaller, the chromate solution could have been used as a standard. The second critical change takes place when the CCC thickness is greater than $10 \mu \mathrm{m}$, when the intensity no longer increases with increasing CCC thickness. The continued increase in the total $\mathrm{Cr}$ with time in Fig. $9 \mathrm{~b}$ indicates that this stage had not been reached. The fraction of $\mathrm{Cr}(\mathrm{VI})$ approached a value of around $40 \%$, close to that observed for the other in situ measurements, indicating that the CCC was dominating the observed fluorescence intensity. From Fig. 2, this occurs at a CCC thickness of $1 \mu \mathrm{m}$, indicating the film was less than this thickness at the end of the exposure time. Generally, the thickness quoted for the CCC is in the range of a few tens of nanometers. ${ }^{23,24}$ Katzman et al. give values of $70 \mathrm{~nm}$ on AA1100, which remained constant for 4 to $16 \mathrm{~min}^{23}$ The difference between these and the results in Fig. 9 where the CCC continued to grow strongly suggests that the CCC is composed of an inner and outer layer that can be removed on rinsing.

\section{Conclusion}

Three techniques have been explored to demonstrate the in situ formation of chromate conversion coatings on pure Al using X-ray absorption spectroscopy. Novel cells were used to observe the growth on commercial Al alloys (AA2024-T3, AA1100, and AA7075-T6), and a series of binary solid solution Al-Cu alloys by in situ XANES measurements using a new type of electrochemical cell. The techniques we employed allowed the determination of hexavalent chromium $[\mathrm{Cr}(\mathrm{VI})]$ and total chromium $[\mathrm{Cr}($ total $)]$ in conversion coatings as a function of exposure time to a chromate solution. All measurements showed an extremely rapid initial growth of the conversion coating. With $\mathrm{Cu}-\mathrm{Al}$ alloys there was a delay in the growth, followed by approximately linear kinetics. Extended time measurements were carried out on an $\mathrm{Al}-0.2 \% \mathrm{Cu}$, which demonstrated that that the conversion coating continued to grow for $1 \mathrm{~h}$. A distinctly decreasing rate of growth was observed with A2024, and an approximately linear growth was apparent for AA1100 after the rapid initial behavior. The growth kinetics of AA1100 and AA2024 could not be directly attributed to $\mathrm{Cu}$ alloying alone, as shown by the $\mathrm{Al}-\mathrm{Cu}$ alloy results, suggesting that microstructural heterogeneity may play an important role in establishing overall CCC growth kinetics. Measurements on AA7075-T6 were unsuccessful because the $\mathrm{Cr}$ in alloy dominated the $\mathrm{Cr}$ measurements. For all specimens the proportion of $\mathrm{Cr}(\mathrm{VI})$ in the coatings becomes approximately constant after $180 \mathrm{~s}$ of exposure time as the coatings continue to grow.

\section{Acknowledgments}

The authors thank Kenneth Sutter for technical support and Thomas A. Lograsso of Ames Laboratories, Iowa for supplying the aluminum-copper alloys. This work was carried out at Brookhaven National Laboratory under the auspices of the U.S. Department of Energy, Division of Materials Science, Office of Basic Energy Sciences under contract no. DE-AC02-76CH00016. K.S. was supported by the Air Force Office of Scientific Research, contract no. F4962096-1-0479. R.G.B. and V.N.L. thank Strategic Environmental Research and Development for support during the execution of this work.

Brookhaven National Laboratory assisted in meeting the publication costs of this article.

\section{References}

1. P. Campestrini, G. Goeminne, H. Terryn, J. Vereecken, and J. H. W. de Wit, J. Electrochem. Soc., 151, B59 (2004).

2. G. Goeminne, A. Hubin, H. Terryn, and J. Vereecken, Electrochim. Acta, 47, 1925 (2002).

3. B. Vuillemin, R. Oltra, H. Perrot, C. Sauvage, and O. Neel, J. Electrochem. Soc., 151, C229 (2004).

4. A. J. Davenport, H. S. Isaacs, G. S. Frankel, A. G. Schrott, C. V. Johnes, and M. A. Russak, J. Electrochem. Soc., 138, 337 (1991).

5. G. S. Frankel, A. G. Schrott, A. J. Davenport, H. S. Isaacs, C. V. Johnes, and M. A. Russak, J. Electrochem. Soc., 141, 83 (1994).

6. A. J. Davenport, H. S. Isaacs, J. A. Bardwell, B. MacDougall, G. S. Frankel, and A. G. Schrott, Corros. Sci., 35, 19 (1993).

7. L. J. Oblonsky, A. J. Davenport, M. R. Ryan, H. S. Isaacs, and R. C. Newman, J. Electrochem. Soc., 144, 2398 (1997).

8. M. Toney and J. McBreen, Electrochem. Soc., 2(1), 22 (1993).

9. J. S. Wainright, O. J. Murphy, and M. R. Antonio, Corros. Sci., 33, 281 (1992).

10. C. S. Jeffcoate, H. S. Isaacs, A. J. Aldykiewicz, and M. P. Ryan, J. Electrochem Soc., 147, 540 (2000).

11. V. Laget, C. S. Jeffcoate, H. S. Isaacs, and R. G. Buchheit, J. Electrochem. Soc., 150, B425 (2003).

12. M. W. Kendig, A. J. Davenport, and H. S. Isaacs, Corros. Sci., 34, 41 (1993).

13. F. W. Lytle, R. B. Greegor, G. L. Bibbins, K. Y. Blohowiak, R. E. Smith, and G. D. Tuss, Corros. Sci., 37, 349 (1995).

14. M. F. Toney, J. G. Gordon, M. G. Samant, G. L. Borges, O. R. Melroy, D. Yee, and L. B. Sorensen, Phys. Rev. B, 45, 9362 (1992).

15. J. E. DeVilbiss, J. X. Wang, B. M. Ocko, K. Tamura, R. R. Adzic, I. A. Vartanyants, and I. K. Robinson, Electrochim. Acta, 47, 3057 (2002).

16. J. W. Criss, Report No. DOD-00065, Naval Research Laboratory, Washington, DC (1977).

17. L. Xia, E. Akiyama, G. Frankel, and R. McCreery, J. Electrochem. Soc., 147, 2556 (2000).

18. G. M. Brown, K. Shimizu, K. Kobayashi, G. E. Thompson, and G. C. Wood, Corros. Sci., 33, 1371 (1992). 
19. M. Kendig, R. Addison, and S. Jeanjaquet, J. Electrochem. Soc., 146, 4419 (1999).

20. R. Waldrop and M. W. Kendig, J. Electrochem. Soc., 145, L11 (1998).

21. W. R. McGovern, P. Schmutz, R. G. Buchheit, and R. L. McCreery, J. Electrochem. Soc., 147, $4494(2000)$

22. P. Campestrini, H. Terryn, J. Vereecken, and J. H. W. de Wit, J. Electrochem. Soc., 51, B359 (2004).
23. H. A. Katzman, G. M. Malouf, R. Bauer, and G. W. Stupian, Appl. Surf. Sci., 2, 416 (1979).

24. P. L. Hagens and C. M. Haas, Surf. Interface Anal., 21, 65 (1994).

25. Aluminum Standards and Data 1978 Metric SI, p. 93, The Aluminum Association, Inc., Washington D.C. (1978). 